\title{
Intra-Medullary Screw Fixation Comprehensive Technique Guide for Metacarpal and Phalanx Fractures: Pearls, and Pitfalls
}

\author{
John Chao, $M D^{1 *}$, Anup Patel, MD, MBA ${ }^{2}$ and Ajul Shah, $M D^{3}$ \\ ${ }^{1}$ Division of Plastic and Reconstructive Surgery, Rutgers New Jersey Medical School, Newark, USA \\ ${ }^{2}$ Orlando Hand Surgery Associates Orlando, USA \\ ${ }^{3}$ The Institute for Advanced Reconstruction Shrewsbury, USA
}

\begin{abstract}
Phalangeal and metacarpal fractures are the second and third most common upper extremity fractures after distal radius fractures with varying methods of fixation techniques. Intramedullary screw fixation is an increasingly preferred method of fixation. Benefits include early range of motion, faster recovery, limited dissection, and limited complications. Improper technique, which is readily avoidable, can lead to suboptimal results. This paper aims to summarize the biomechanics of intramedullary screw fixation and outline appropriate technique of placing headless compression screws for metacarpal and phalangeal fractures. We discuss indications, preoperative workup, technical pearls and pitfalls to encourage surgeons to add this technique to their arma mentarium and improve outcomes.
\end{abstract}

\section{Keywords}

Metacarpal fracture, Phalanx Fracture, Intra-medullary screw, Headless compression screw, Open reduction internal fixation

\section{Introduction}

Phalangeal and metacarpal fractures are the second and third most common upper extremity fractures after distal radius, respectively [1-4]. For unstable fractures of the proximal phalanx and metacarpal, no method of fixation has been determined to be superior to another. Plate fixation is able to provide reduction and stability for early range of motion with mixed clinical results [5-7]. Reported complications requiring surgical intervention include stiffness, proximal interphalangeal joint (PIPJ) fixed flexion contracture, and extensor lag $[5,6]$. There are minimally invasive techniques including the use of k-wires, lag screws, cerclage wiring, external fixation that limit soft tissue dissection. These options have drawback of malunion, nonunion, infection, hard ware removal and stiffness [8-10].

Intramedullary screw fixation (IMF) is an emerging alternative to k-wire or plate fixation in treating displaced and unstable phalangeal and metacarpal fractures. The goal of reconstruction is to provide rigid fixation that can support near immediate range of motion. This prevents stiffness, shortens recovery, allows earlier return to work with minimal complication, ease of fixation, and limited dissection. IMF is a physiologic option that offers rigid stability, early active range of motion, and simplicity of insertion. Pinal, et al. Demonstrate complete fracture healing in 69 patients, mean total active motion of 247 degrees and full return to activity at an average of 76 days [11]. The purpose of this paper is to review intermedullary screw fixation of metacarpal and phalanx fractures while elucidating the pearls and pitfalls to maximize successful surgical outcomes.

\section{Biomechanical Properties}

IMF biomechanical properties are well described in orthopedic literature as load-sharing devices [12]. Initially, the majority of load and anatomic alignment across fracture is supported by the screw, but as the fracture heals, the load is transfer red to the bone. Two forces that need to be ad-

*Corresponding author: John Chao, MD, Division of Plastic Surgery, Rutgers New Jersey Medical School, 140 Bergen Street, Suite E-1620, Newark, NJ 07103, USA, Tel: 614-517-8521

Accepted: May 11, 2021

Published online: May 13, 2021

Citation: Chao J, Patel A, Shah A (2021) Intra-Medullary Screw Fixation Comprehensive Technique Guide for Metacarpal and Phalanx Fractures: Pearls, and Pitfalls. J Orthop Surg Tech 4(1):266-275 
Citation: Chao J, Patel A, Shah A (2021) Intra-Medullary Screw Fixation Comprehensive Technique Guide for Metacarpal and Phalanx Fractures: Pearls, and Pitfalls. J Orthop Surg Tech 4(1):266-275

equately addressed are bending and torsional forces during MCP or PIP joint flexion. In biomechanical studies, the surface area of bone resisting bending is a function of using a screw wide enough to engage the intramedullary cortical bone with good purchase, while avoiding blow out, and utilizing the longest allowable screw length on each side of the fracture. As the width of the nail increases, there is more bone-to-nail friction, thereby, making the fixation more resistive to both bending and torsional forces [13].

Metacarpal and phalanx fractures have low rates of nonunion regardless of fixation technique [14-18]. Although most intramedullary screw fixation devices rely on variable pitch threads to achieve compression, in these types of fractures, compression is not mandatory for success ful healing. This is in stark contrast to scaphoid fractures that rely on compression of the fracture site for optimal healing [19]. Fixation can be achieved with a variety of screw designs-variable pitch fully threaded, variable pitch partially threaded, consistent pitch fully threaded. There is some evidence to indicate a consistent pitch that avoids compression may allow fractures which otherwise tend to be over-compressed to be more reliably treated (e.g., long oblique or comminuted fractures of the metacarpal).

\section{Indications}

This technique is ideal for patients needing swift return to activity with minimal to no need for splinting. Although occupational therapy is always recommended for patients undergoing fracture fixation, this fixation method is strong enough to support early range of motion in patients who may be reticent or unable to attend hand therapy; there by, providing them an opportunity to avoid the stiffness that may be associated with more traditional methods of fixation, namely K-wires. In patients at high risk of loss to follow-up or non-compliance, this technique prevents prolonged K-wire fixation, potential tract infection, and self-removal of wires.

In general, IM fixation is indicated in metacarpal and phalanx fractures that are displaced and unstable. In metacarpal shaft fractures, transverse and short oblique patterns $1<2$ times the shaft diameter) are reasonable indications. The surgeon must note the potential for minimal fracture segment displacement with the compressive mechanism of compression screws, albe it generally irrelevant from a clinical stand point. Other indications include those situations where early ROM is advisable and potentially mandatory, multiple metacarpal shaft fractures, open fracture with severe soft tissue injury, and osteotomies.

\section{Absolute/Relative Contraindications}

Due to the compressive mechanism associated with compression screws, long oblique fractures ( $>2$ times the shaft diameter) are at risk of fracture displacement and shortening. Comminuted fractures are also at risk for shortening and over compression when treated with IM compression screws, and a number of complex configurations (e.g. fragment lag screw) have been developed to countermand this issue [11]. These relative contraindications can be potentially countermanded by use of non-variable pitch screws since there is no compres-
Table 1: HCS diameter general recommendations.

\begin{tabular}{|l|l|}
\hline Index and Middle Metacarpal & $3.5-4.0 \mathrm{~mm}$ \\
\hline Ring Metacarpal & $2.5-3.0 \mathrm{~mm}$ \\
\hline Small Metacarpal & $3.5-4.5 \mathrm{~mm}$ \\
\hline Proximal phalanx & $2.5-3.0 \mathrm{~mm}$ \\
\hline
\end{tabular}

sive or shortening mechanism $[19,20]$. Metacarpal fractures of the proximal $1 / 3$ make passing distal screw thread past fracture difficult. However, Hoang, et al. describe using an anterograde approach to fixate these fractures [21].

Head-splitting fractures are avoided due to risk in worsening fracture with placement of screw. Lastly, infection and fractures in children with open physis is an absolute contraindication to IM fixation [11].

\section{Preoperative Planning}

Standard history and physical should include handedness, occupation, physical exam including rotation and shortening, and chronicity of fracture. Radiograph evaluation is important to note comminution, location of fracture, and fracture pattern (transverse, short oblique, long oblique, and butterfly segments).

The full width of the bone and the narrowest width of medullary canal isthmus should be measured. The surgeon should be mindful that each metacarpal has consistent differences in width, as the ring finger has the narrowest isthmus at average of $2.6 \mathrm{~mm}$ and small finger largest at $3.6 \mathrm{~mm}[22,23]$. The narrowest canal width in metacarpal bones should be measured in the PA view and narrowest canal width of the phalanx is measured on the lateral radiograph. The width of the narrowest part of the isthmus is the most important factor to guide the choice of the appropriately sized screw to ensure contact between screw and bone without causing blowout. General guidelines are outlined below with preference for wider diameter screw after canal reaming, understanding that outliers exist both smaller and larger (Table 1).

\section{Operative Technique for Metacarpal Fractures} Retrograde placement (Figure 1)

The operation is performed under regional block with sedation, under general anesthesia, or using wide awake local anesthetic no tourniquet techniques. After prep, attempts at closed reduction under fluoroscopy are performed. If rapid reduction cannot be obtained in a closed manner, then an open reduction is performed. A $1.5 \mathrm{~cm}$ transverse incision is made dorsally over the metacarpal head and neck with \#15 blades. Dissection is carried to the extensor apparatus and the extensor tendon split longitudinally, exposing metacarpal head. Truly percutaneous considerations are addressed below. Prior to driving the guide wire, the appropriately sized screw is overlaid over the bone and fluoroscopy is used to confirm appropriate sizing. This includes the appropriate width and length. Then, the appropriate guide wire is selected and driven into the dorsal $1 / 3$ of metacarpal head and drilled retrograde to level of fracture with help of c-arm. The fracture is then reduced, confirmed under fluoroscopy and the 


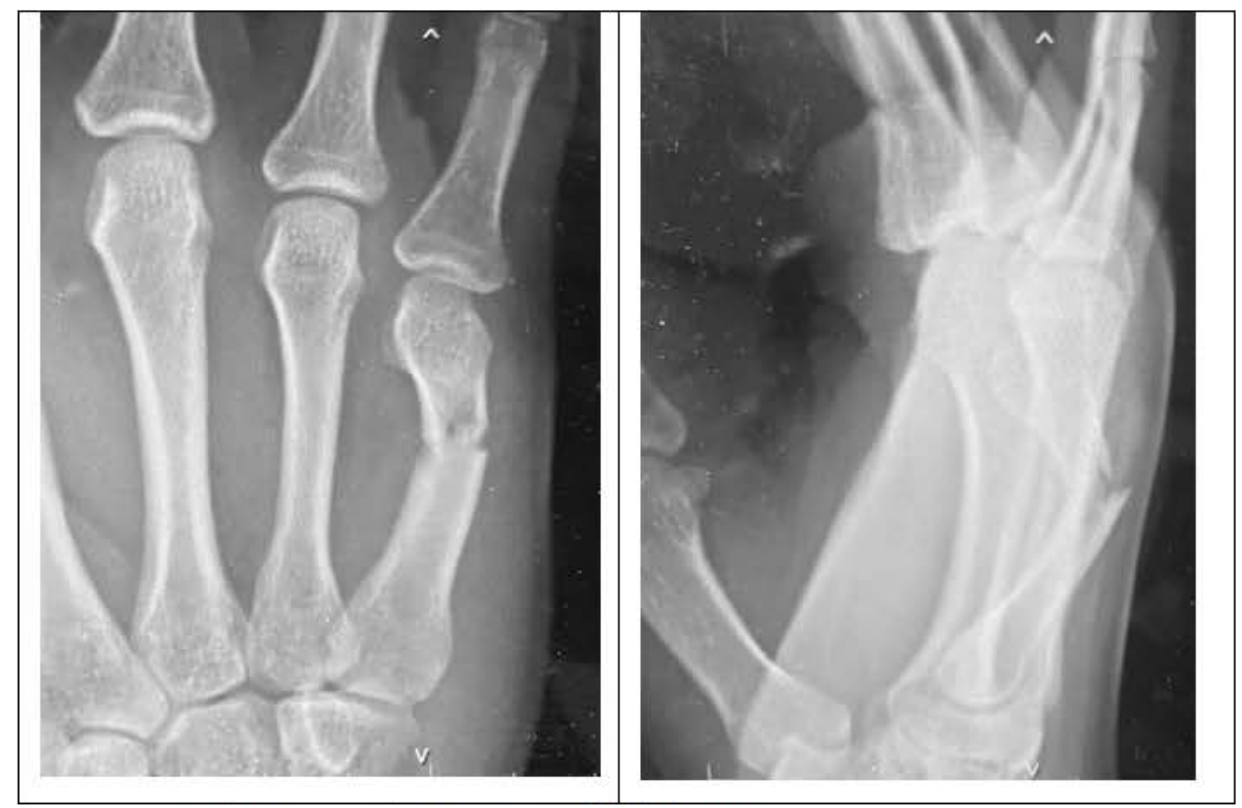

Figure 1a: $5^{\text {th }}$ metacarpal transverse shaft fracture.

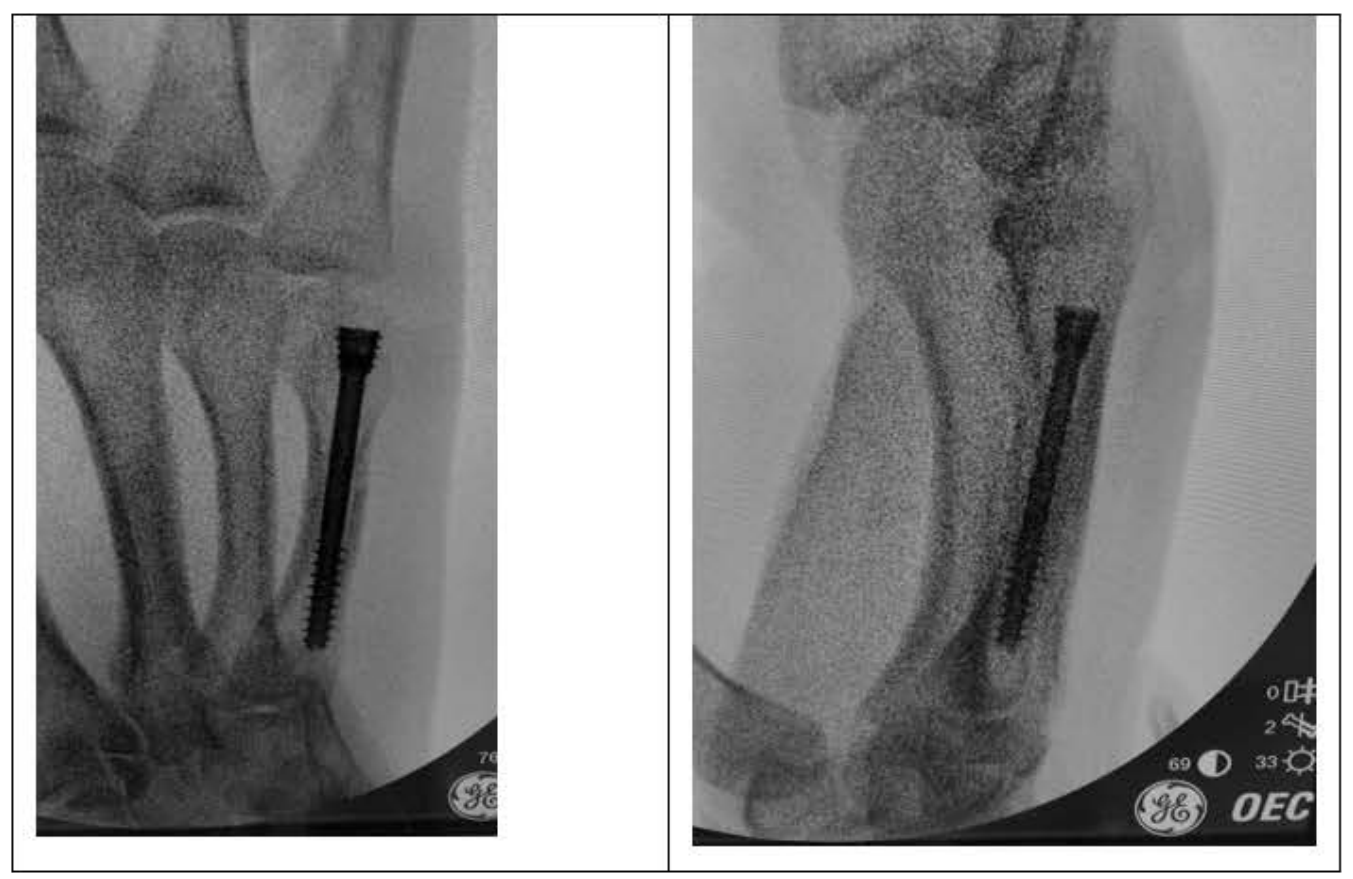

Figure 1b: Immediate post-op after $3.5 \mathrm{~mm}$ headless compression screw.

K-wire is driven across the fracture site to base of metacarpal. The flexion cascade is evaluated, and time is spent in assuring the absence of malrotation. Measurements of the K-wire are performed and 4-6 $\mathrm{mm}$ are generally subtracted to get final screw length (for partially threaded screws, measurements must accommodate for the distal threads to be placed past the fracture line). The $\mathrm{K}$-wire is then advanced through the carpometacarpal joint to avoid inadvertent removal when reaming over the wire. The metacarpal is drilled just past the fracture site while ensure the narrowest part of the canal is reamed in order to accommodate the screw threads. In order to prevent rotational deformity during screw placement, the fingers are all flexed into the palm to set the appropriate flex- ion cascade and prevent malrotation. The screw is then hand driven with the fingers flexed.

The screw should engage the canal with good purchase as the threads of the screw engage the intramedullary cortical bone and should be buried ideally just beneath the subchondral bone. The surgeon should confirm screw placement under fluoroscopy and again check for malrotation. The guidewire is then removed. Extensor tendon and skin are closed. A bulky soft dressing is placed immediately post-operative and removed between 3-5 day for early ranges of motion to begin. There is no need for rigid immobilization if good purchase is achieved. 
Citation: Chao J, Patel A, Shah A (2021) Intra-Medullary Screw Fixation Comprehensive Technique Guide for Metacarpal and Phalanx Fractures: Pearls, and Pitfalls. J Orthop Surg Tech 4(1):266-275

The patient is expected to reach full ROM by 4 weeks, start strengthening and progressively heavier activities 4-8 weeks. Unlimited unrestricted usage is recommended by 8 weeks.

\section{Operative Technique for Phalangeal Fractures}

\section{Proximal phalanx anterograde intra-articular placement (Figure 2)}

The operation is performed under regional block with sedation, under general anesthesia, or using wide awake local anesthetic no tourniquet techniques. Attempts at closed reduction under fluoroscopy are performed. If rapid reduction cannot be obtained in a closed manner, then a limited open reduction is performed.

The narrowest portion of the intra-medullary canal helps determine the size of the screw. Both trans-articular and intra-articular approaches have been described, with our preference for single screw with intra-articular placement [24]. Of note, the uses of two anterograde screws have been shown as a viable option for proximal phalanx fracture fixation. In a limited series, two screws showed improved rotational stability compared to single screw [25].

After closed reduction under fluoroscopy, a small transverse incision of no more than $0.5 \mathrm{~cm}$ in length is made over the metacarpophalangeal (MP) joint, which is then flexed $60^{\circ}$ to $75^{\circ}$ while the proximal end of the phalanx is translated dorsally to expose articular surface of proximal phalanx base. Prior to driving the guide wire, the appropriately sized screw is overlaid over the bone and fluoroscopy is used to confirm appropriate sizing. This includes the appropriate width and

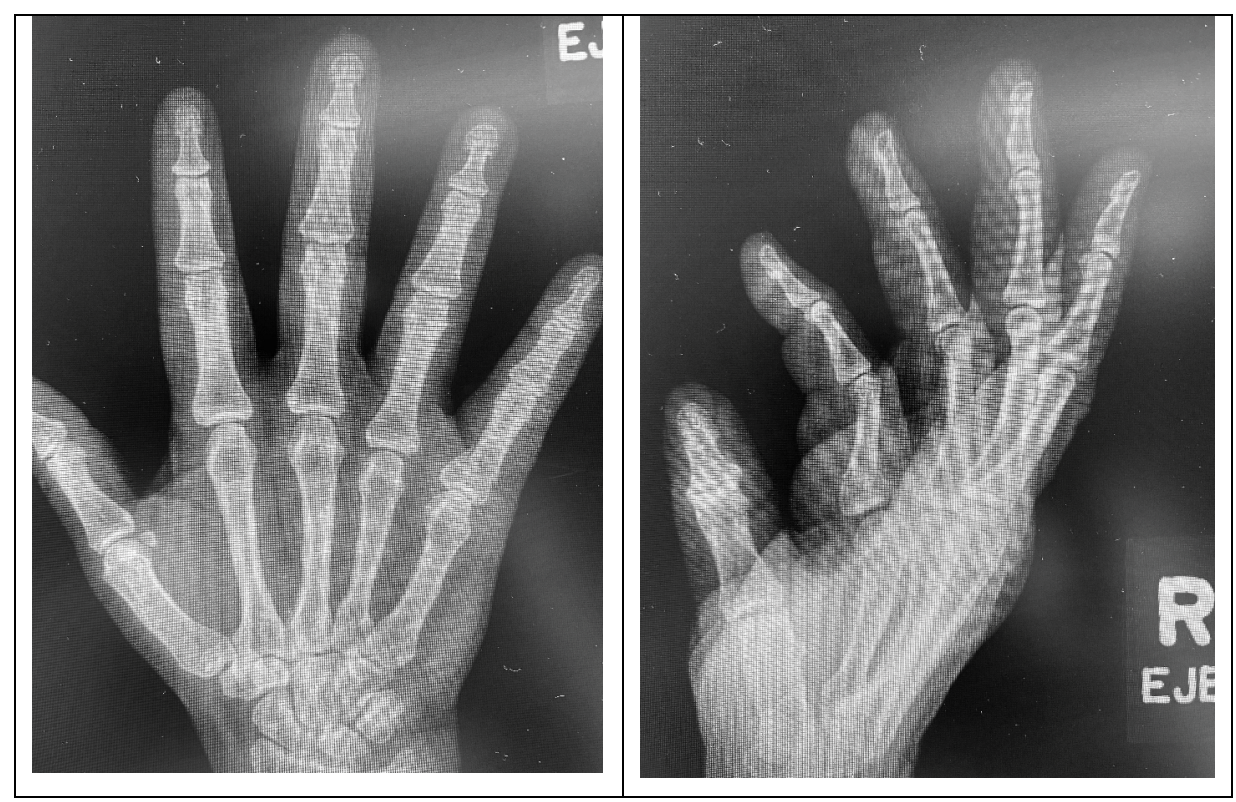

Figure 2a: Small finger proximal phalanx transverse base fracture.

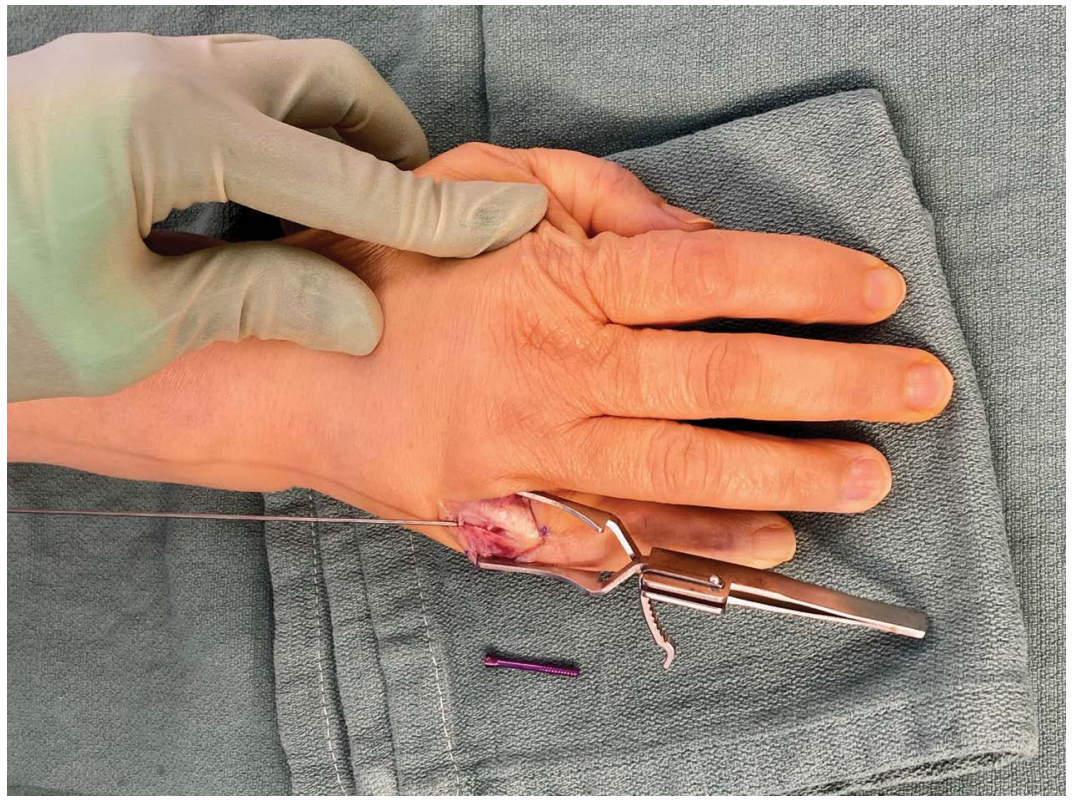

Figure $\mathbf{2 b}$ : Intraoperative anterograde placement of $2.5 \mathrm{~mm}$ headless compression screw, sparing extensor tendons. 


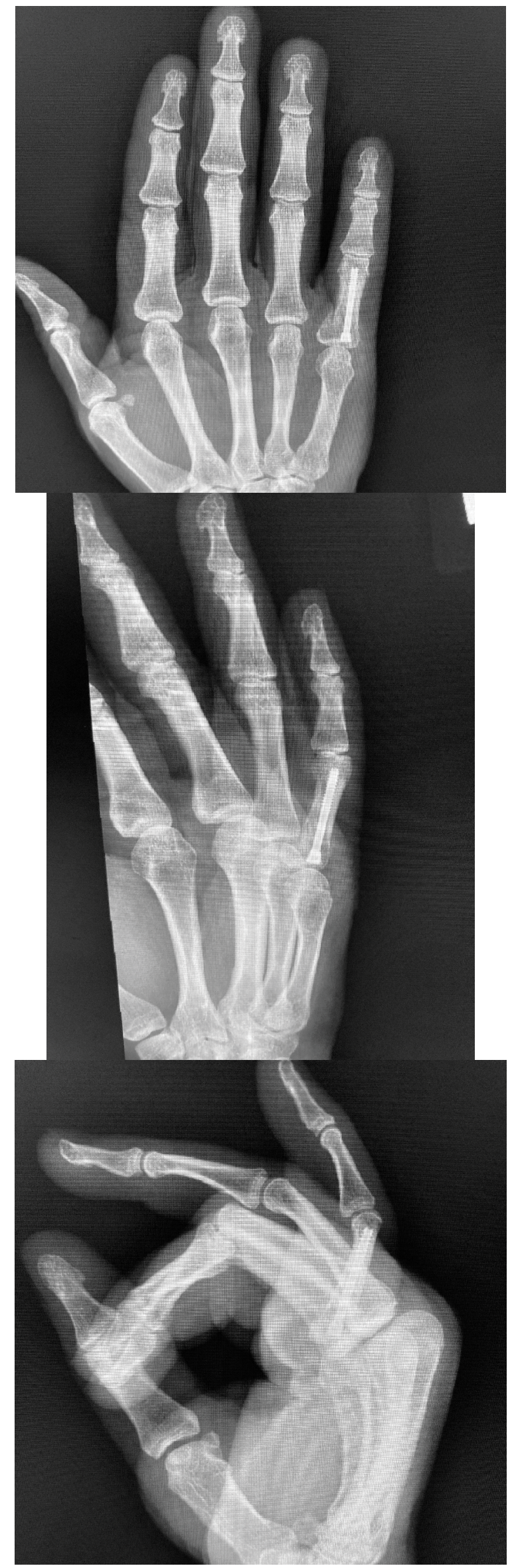

Figure 2c: 5-month post op with routine healing. 
length. Under fluoroscopic control, insert the appropriate guidewire dorsally through the flexed MCP joint into the center of the proximal phalanx base in the longitudinal axis. Advance the wire into distal cortex to avoid inadvertent removal of wire during reaming. Drill the phalanx just past the fracture site. In order to ensure an absence of rotational deformity during screw placement, flex all fingers into the palm to set the appropriate flexion cascade and prevent malrotation. A 2.5-3.0 $\mathrm{mm}$ screw is then hand driven under direct visualization with the fingers flexed. Patients are placed into a soft dressing if stable fixation is achieved and to start hand therapy within 3-5 days.

\section{Complications, Pearls and Pitfalls \\ Concern for articular cartilage disruption}

Several studies have looked at the size of articular defects from placement of intramedullary screws. Ten Berg performed 3-dimensional CT quantitative analysis looking at retrograde $2.4 \mathrm{~mm}$ and $3.0 \mathrm{~mm}$ HCS fixation of metacarpal fractures to determine the extent of articular cartilage violation in 32 metacarpals [26]. They compared the metacarpal head articular and screw insertion hole surface area. The screw articular defect over the dorsal central aspect of the joint surface makes contact with only the base of the proximal phalanx during joint hyperextension due to the intrinsic shape of $M C$ head and dorsal entry point of HCS. The phalangeal base does not engage the entry site for $95-96 \%$ of the 120 -degree sagittal arc. This data demonstrates that the screw surface defect that contacts the proximal phalanx base in range of motion is minimal. Furthermore, headless compression screw is the gold standard for treating scaphoid fractures, a bone that has $80 \%$ articular surface [27]. Although there is no literature analyzing scaphoid articular defect, screws are placed without concern for cartilage violation. Overall, the concern for articular cartilaginous disruption appears to be largely theoretical.
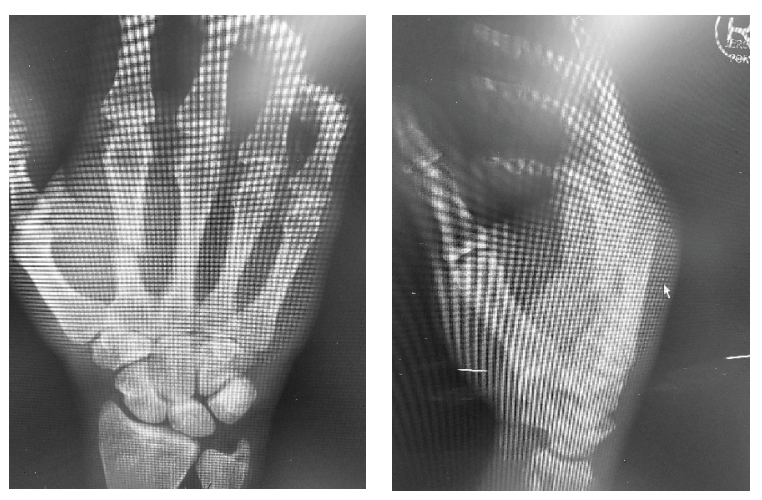

Figure 3a: Index finger transverse shaft fracture with sub-millimeter medullary isthmus on AP view.
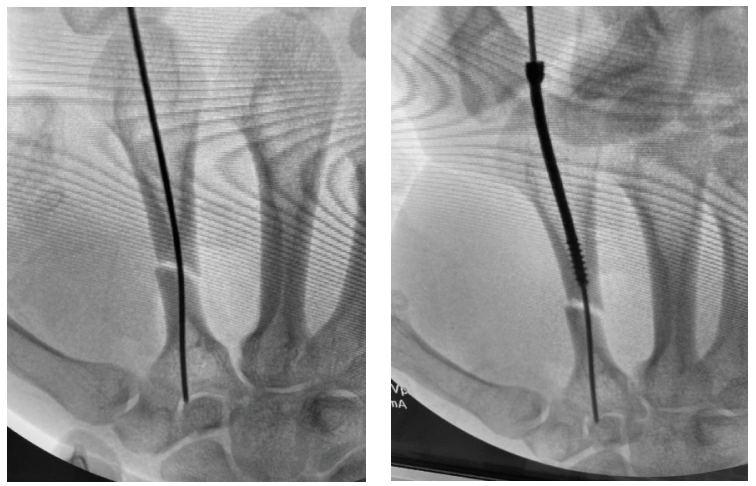

Figure 3b: Placement of headless compression screw in $2^{\text {nd }}$ metacarpal without pre-drilling resulting in bent screw.

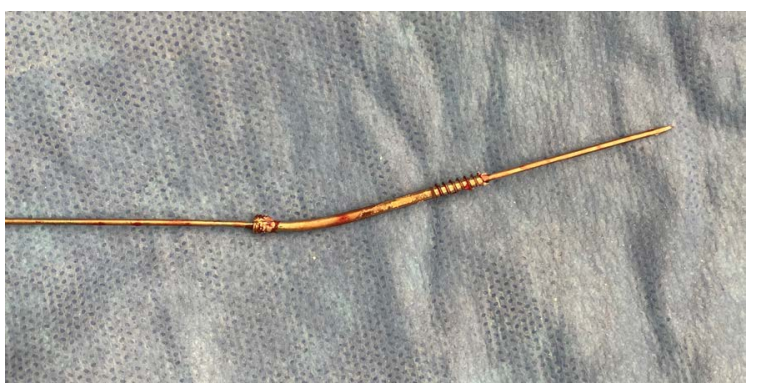

Figure 3c: Bent screw requiring removal. 


\section{Percutaneous placement}

Considerations can be given to a true percutaneous technique when taking into consideration the potential for injury to the extensor mechanism. Urbanschitz, et al. demonstrated an avoidance of extensor tendon injury with open technique when compared to percutaneous in both metacarpal and phalangeal fractures [28]. Upon dissection analysis of tendon, there was significant less damage in open technique $(p<0.001)$ due to direct tendon visualization and protection. The authors also found higher incidence of tendon injury in phalanges compared to metacarpal percutaneous technique regardless of anterograde or retrograde. However, it is critical to note that ALL recorded tendon injuries were less than $50 \%$ of the entirety of the tendon. As classic teaching follows that no acute surgical treatment is indicated in extensor tendon injuries less than $50 \%$ tendon diameter [29], the damage to the extensor tendon during percutaneous techniques may not actually be clinically relevant. To determine whether open or percutaneous technique is superior in outcomes, further clinical comparison is needed. In-vitro studies have shown that extensor tendon rupture after drill injury is rare and even lacerations of up to $75 \%$ may not fail under physiological load [30].

\section{Respect the canal and reaming}

The authors want to emphasize the importance of proper sizing the screw to the canal isthmus diameter through the use of preoperative imaging as described above. An oversized screw combined with reaming may risk a blow-out fracture upon screw insertion. Furthermore, placing a screw that is wider than the canal without reaming can lead to disastrous outcomes including bending or breakage of the screw (Figure 3). Especially in young patients, the cortical bone is too firm for self-tapping screws to pass without reaming. An undersized screw does not follow the appropriate biomechanical properties and will not engage inner cortex for maximal stability-there fore, the fracture will not be rigidly fixated. If it is difficult to pass a K-wire for the chosen screw width due to the narrowness of the canal, a K-wire one size down can be placed and the bone can be reamed with the appropriate size drill bit followed by upsizing the K-wire and the drill bit to the chosen screw width.

\section{Multiple fractures (Figure 4)}

We present a demonstrative case to document the clear utility of intramedullary screws in multiple fractures in order to demonstrate the excellent range of motion that can be

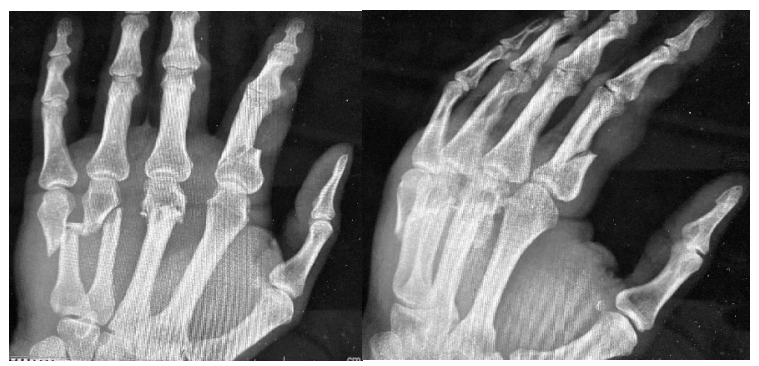

Figure 4a: $3-5^{\text {th }}$ metacarpal neck short oblique fracture and 1st proximal phalanxshort oblique base fracture.

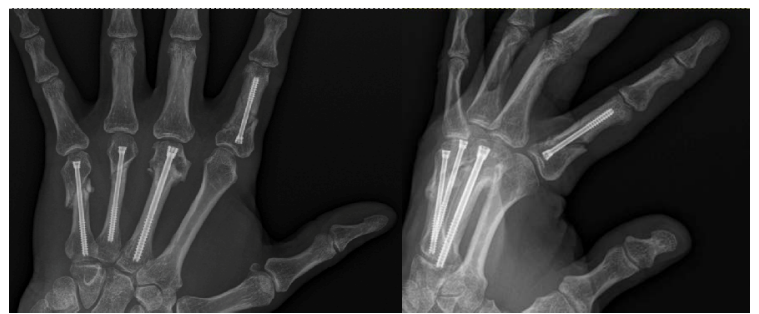

Figure 4b: Placement of $3.0 \mathrm{~mm}$ (small and ring finger), $3.5 \mathrm{~mm}$ (middle finger), and $2.5 \mathrm{~mm}$ (index proximal phalanx) headless compression screws.

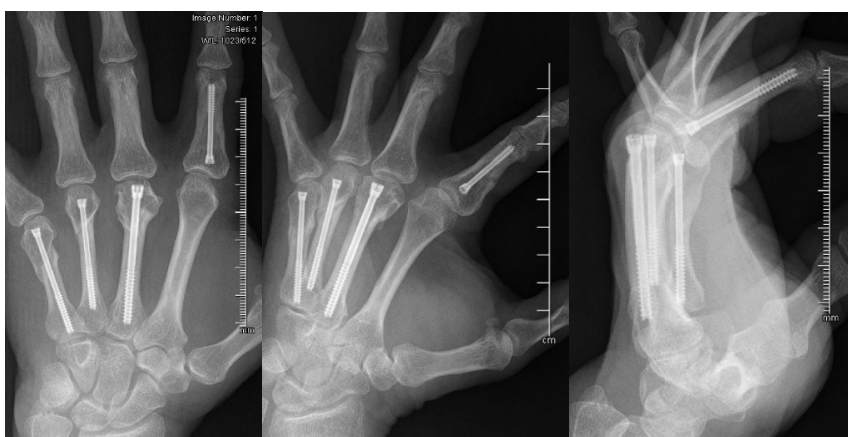

Figure 4c: 6-month post op with routine healing. 
Citation: Chao J, Patel A, Shah A (2021) Intra-Medullary Screw Fixation Comprehensive Technique Guide for Metacarpal and Phalanx Fractures: Pearls, and Pitfalls. J Orthop Surg Tech 4(1):266-275

Table 2: Advantages and Disadvantages of HCS.

\begin{tabular}{|c|c|}
\hline Advantages & Disadvantages \\
\hline $\begin{array}{l}\text { - } \text { Immediate range of motion with excellent stability } \\
\text { - } \quad \text { simit dissection that could cause tendon irritation and } \\
\text { - } \\
\text { - } \quad \text { Corformed quickly and reliably } \\
\text { - } \quad \text { Limit visible incisional scarring } \\
\text { - Limit reliance on unreliable patients } \\
\text { - Less skewering of bone, more stability than K-wires } \\
\text { - No pin tract infection } \\
\text { - No hardware removal }\end{array}$ & $\begin{array}{l}\text { - Increase cost vs. pins, less than plates } \\
\text { - } \quad \text { Potential canal-screw mismatch } \\
\text { - } \quad \text { Technique learning curve } \\
\text { - } \quad \text { Theoretical concern of articular cartilage violation }\end{array}$ \\
\hline
\end{tabular}

achieved in high energy trauma. Multiple fractures lead to significant swelling and significant stiffness, which often lead to major limitations in range of motion. This is an excellent indication for this technique because patients can engage in early active motion for better and faster return to preoperative range of motion. IMF technique can be effectively performed in 15-20 minutes for each bone and the proposed technique can limit both operative time as well as periosteal stripping and soft tissue dissection associated with plate fixation. This thereby minimizes the chances of soft tissue adhesions, rate of tenolysis, permanent swelling, scarring and stiffness. Further more, the technique allows for near immediate range of motion even in the face of multiple fractures due to the stability provided by the construct.

\section{Anterograde vs. retrograde for phalanx}

Intermedullary screws for proximal phalanx fixation has been described with both anterograde through metacarpophalangeal joint and retrograde approaches through the proximal interphalangeal joint [31,32]. The retrograde technique is technically less demanding but a larger relative area of the distal joint surface of the proximal phalanx is violated in comparison with the antegrade technique. The mean head of proximal phalanx articular surface defects were $13 \%$ to $18 \%$ for a $2.5 \mathrm{~mm}$ screw, and $19 \%$ to $25 \%$ for a $3.0 \mathrm{~mm}$ screw, estimated from computed tomographic scans of healthy fingers [11]. Further more, the central slip of the extensor mechanism may be compromised by this retrograde technique $[26,31,33]$. We prefer the anterograde approach whenever possible as violation of the proximal interphalangeal joint in our anecdotal experience does appear to confer diminished outcomes in terms of range of motion.

\section{Flexion of fingers into palm during screw place- ment}

To prevent easy malrotation as screw engages strong cortical bone within canal, keep the fingers flexed into palm to tighten intermetacarpal ligaments and set appropriate cascade.

\section{Discussion}

IMF is emerging as a popular method of fixating metacar- pal and phalangeal fractures. The advantages and disadvantages of this technique are outlined in (Table 2). A meta-analysis by Beck, et al. Examined 169 metacarpal and reported no major complications, $100 \%$ union rate, and full composite fist range of motion with average follow-up time of 11 months [33]. The major advantage of IMF over other techniquesis faster recovery to daily living and work-related activities; furthermore, it leads to lower operative time, costs, soft tissue trauma, periosteal stripping, and extensor tendon complications than plating.

Advantages over k-wire fixation include a significantly lower rate of stiffness stemming from the benefits of early range of motion and limited immobilization. The complications rates for IMF are much lowerwhen compared to K-wire fixation, which range from $15-18 \%$ including pin tract infection (7\%), pin loosening or migration (5\%), and nonunion $(4 \%)[8,9]$.

Multiple studies demonstrate plates to have higher breaking strength than HCS $[24,34,35]$. Melamed, et al. found an average load of failure in $2.4 \mathrm{~mm}$ IM screw of $75 \pm 20 \mathrm{~N}$ in human cadaveric bone models [36]. This is compared to an average load of failure of over $350 \mathrm{~N}$ in plate constructs. But, it is important to note that testing was done with a 4-point bending apparatus that in no way simulates the stress incurred during true in vivo physiologic loads. (Of note, the average bending moment during metacarpophalangeal joint flexion has been reported to be $0.35 \mathrm{Nm}$ [37]) Plates and screws may allow superior strength in vitro but have higher rates of complications and higher costs in vivo without clear benefit over IMF. Fusetti, et al. reported complications including stiffness, delayed healing, plate loosening or breakage, complex regional pain syndrome, and deep infection in $35 \%$ of patients [38]. Page and Stern found a similar major complication rate of $36 \%$ in 105 metacarpal and/or phalangeal fractures fixated with plates. IMF allow for early mobilization while also avoiding the multiple planes of dissection, soft tissue scarring, periosteal stripping, and soft tissue swelling that is associated with plate and screw fixation.

\section{Summary}

IM screw fixation is a powerful option for metacarpal and phalanx fixation that allows rigid stability enabling early re- 
turn of function with excellent rates of union and total active motion. With knowledge of technical pearls presented in this paper, common mistakes can be avoided to improve efficiency of screw placement and optimize patient outcomes.

\section{Conflicting Interests}

The author(s) declare no potential conflicts of interest with respect to the research, authorship, and/or publication of this article.

\section{Funding}

The author(s) received no financial support for the research, authorship, and/or publication of this article.

\section{Informed Consent}

Not applicable.

\section{Ethical Approval}

Not applicable.

\section{Contributorship}

JC and AS researched literature and conceived the study. $\mathrm{JC}$ wrote the first draft of the manuscript. All authors reviewed and edited the manuscript and approved the final version of the manuscript.

\section{Acknowledgements}

None.

\section{References}

1. Nakashian MN, Pointer L, Owens BD, et al. (2012) Incidence of metacarpal fractures in the US population. Hand (NY) 7: 426-430.

2. Court-Brown CM, Caesar B (2006) Epidemiology of adult fractures: A review. Injury 37: 691-697.

3. Karl JW, Olson PR, Rosenwasser MP (2015) The epidemiology of upper extremity fractures in the united states, 2009. J Orthop Trauma 29: e242-e244.

4. Chung KC, Spilson SV (2001) The frequency and epidemiology of hand and forearm fractures in the United States. J Hand Surg Am 26: 908-915.

5. Page SM, Stern PJ (1998) Complications and range of motion following plate fixation of metacarpal and phalangeal fractures. $J$ Hand Surg Am 23: 827-832.

6. Robinson LP, Gaspar MP, Strohl AB, et al. (2017) Dorsal versus lateral plate fixation of finger proximal phalangeal fractures: a retrospective study. Arch Orthop Trauma Surg 137: 567-572.

7. Verver D, Timmermans L, Klaassen RA, et al. (2017) Treatment of extra-articular proximal and middle phalangeal fractures of the hand: A systematic review. Strategies Trauma Limb Reconstr 12: $63-76$

8. Botte MJ, Davis JLW, Rose BA, et al. (1992) Complication of smooth pin fixation of fracture and dislocation in the hand and wrist. Clin Orthop 276: 194-201.

9. Stahl S, Schwartz O (2001) Complications of K-wire fixation of fractures and dislocations in the hand and wrist. Arch Orthop Trauma Surg 121: 527-530.
10. Eberlin KR, Babushkina A, Neira JR, et al. (2014) Outcomes of closed reduction and periarticular pinning of base and shaft fractures of the proximal phalanx. J Hand Surg Am 39: 1524-1528.

11. Del piñal F, Moraleda E, Rúas JS, et al. (2015) Minimally invasive fixation of fractures of the phalanges and metacarpals with intramedullary cannulated headless compression screws. J Hand Surg Am 40: 692-700.

12. Bong MR, Kummer FJ, Koval KJ, et al. (2007) Intramedullary nailing of the lower extremity: Biomechanics and biology. J Am Acad Orthop Surg 15: 97-106.

13. Russell TA, Taylor JC, LaVelle DG, et al. (1991) Mechanical characterization of femoral interlocking intramedullary nailing systems. J Orthop Trauma 5: 332-340.

14. Wong TC, Ip FK, Yeung SH (2006) Comparison between percutaneous transverse fixation and intramedullary K-wires in treating closed fractures of the metacarpal neck of the little finger. J Hand Surg Br 31: 61-65.

15. Ozer K, Gillani S, Williams A, et al. (2008) Comparison of intramedullary nailing versus plate-screw fixation of extra-articular metacarpal fractures. J Hand Surg Am 33A: 1724-1731.

16. Jupiter JB, Koniuch MP, Smith RJ (1985) The management of delay union and nonunion of the meta-carpals and phalanges. $J$ Hand Surg 10: 457-466.

17. Herbert TJ, Fisher WE (1984) Management of the fractured scaphoid using a new bone screw. J Bone Joint Surg Br 66: 114123.

18. McQueen MM, Gelbke MK, Wakefield A, et al. (2008) Percutaneous screw fixation versus conservative treatment for fractures of the waist of the scaphoid: A prospective randomized study. J Bone Joint Surg $\mathrm{Br}$ 90: 66-71.

19. Boulton CL, Salzler M, Mudgal CS (2010) Intramedullary cannulated headless screw fixation of a comminuted subcapital metacarpal fracture: Case report. J Hand Surg Am 35: 1260-1263.

20. Tobert DG, Klausmeyer M, Mudgal CS (2016) Intramedullary fixation of metacarpal fractures using headless compression screws. J Hand Microsurg 8: 134-139.

21. Hoang D, Huang J (2019) Antegrade intramedullary screw fixation: A novel approach to metacarpal fractures. Journal of Hand Surgery Global Online 1: 229-235.

22. Dunleavy ML, Candela X, Darowish M (2020) morphological analysis of metacarpal shafts with respect to retrograde intramedullary headless screw fixation. Hand (N Y).

23. Okoli M, Chatterji R, llyas A, et al. (2020) Intramedullary headless screw fixation of metacarpal fractures: A radiographic analysis for optimal screw choice. Hand (N Y).

24. Giesen T, Gazzola R, Poggetti A, et al. (2016) Intramedullary headless screw fixation for fractures of the proximal and middle phalanges in the digits of the hand: A review of 31 consecutive fractures. J Hand Surg Eur 41: 688-694.

25. West J, Mason B (2020) Limited Incision Open Reduction and Internal Fixation of Proximal Phalanx Fractures with Headless Screws. Presented at the: 2020 AAHS Annual Meeting.

26. Ten Berg PW, Mudgal CS, Leibman MI, et al. (2013) Quantitative 3-dimensional CT analyses of intramedullary headless screw fixation for metacarpal neck fractures. J Hand Surg Am 38: 322-330.e2.

27. Berger RA (2001) The anatomy of the scaphoid. Hand Clin 17: 525-532. 
28. Urbanschitz L, Dreu M, Wagner J, et al. (2020) Cartilage and extensor tendon defects after headless compression screw fixation of phalangeal and metacarpal fractures. Journal of Hand Surgery (European Volume) 45: 601-607.

29. Griffin M, Hindocha S, Jordan D, et al. (2012) Management of extensor tendon injuries. The Open Orthopedics Journal 6: 36-42.

30. Mahylis JM, Burwell AK, Bonneau L, et al. (2017) Drill penetration injury to extensor tendons: A biomechanical analysis. 12: 301-306.

31. Borbas P, Dreu M, Poggetti A, et al. (2016) Treatment of proximal phalangeal fractures with an antegrade intramedullary screw: A cadaver study. J Hand Surg Eur Vol 41: 683-687.

32. Hand Gaspar MP, Gandhi SD, Culp RW, et al. (2019) Dual Antegrade Intramedullary Headless Screw Fixation for Treatment of Unstable Proximal Phalanx Fractures. Hand (N Y) 14: 494-499.

33. Beck CM, Horesh E, Taub PJ (2019) Intramedullary screw fixation of metacarpal fractures results in excellent functional outcomes: A literature review. Plast Reconstr Surg 143: 1111-1118.
34. Mann RJ, Black D, Constine R, et al. (1985) A quantitative comparison of metacarpal fracture stability with five different methods of internal fixation. J Hand Surg Am 10: 1024-1028.

35. Curtis BD, Fajolu O, Ruff ME, et al. (2015) Fixation of Metacarpal Shaft Fractures: Biomechanical Comparison of Intramedullary Nail Crossed K-Wires and Plate-Screw Constructs. Orthop Surg 7: 256-260.

36. Melamed E, Hinds RM, Gottschalk MB, et al. (2016) Comparison of dorsal plate fixation versus intramedullary headless screw fixation of unstable metacarpal shaft fractures: A biomechanical study. Hand (N Y) 11: 421-426.

37. Vanik RK, Weber RC, Matloub HS, et al. (1984) The comparative strengths of internal fixation techniques. J Hand Surg Am 9: 216221.

38. Fusetti C, Meyer H, Borisch N, et al. (2002) Complications of plate fixation in metacarpal fractures. J Trauma 52: 535-539.

DOI: $10.36959 / 453 / 559$

Copyright: (c) 2021 Chao J, et al. This is an open-access article distributed under the terms of the Creative Commons Attribution License, which permits unrestricted use, distribution, and reproduction in any medium, provided the original author and source are credited. 